\title{
Попов А.C.
}

\section{Прогиб балочной фермы с учетом строительного подъема в зависимости от числа панелей и распределения площадей стержней}

\author{
Popov A.S. \\ The deflection of the girder, including construction hoist, depending \\ on number of panels and the distribution of areas rods
}

\begin{abstract}
Приводится вывод формулы зависимости прогиба плоской статически определимой фермы. Усилия в символьном виде определяются методом вырезания узлов в системе компьютерной математики Maple. Для обобщения решения на произвольное число панелей применен метод индукции
\end{abstract}

Ключевые слова: ферма, деформация, индукция, Maple

\author{
Попов Алексей Сергеевич \\ Студент \\ Национальный исследовательский университет \\ «МЭИ» \\ 2. Москва, ул. Красноказарменная, 14
}

Formula of dependence of deflection of statically determinate flat truss is obtained. Forces in rods in symbolic form are determined by the cut nodes in the system of computer mathematics Maple. To generalize the solution for an arbitrary number of panels the method of induction is applied

Key words: truss, deformation, induction, Maple

\section{Popov Alexey Sergeevich}

Student

National research university "MPEI"

Moscow, Krasnokazarmennaya st., 14

В [1] получено точное выражение для прогиба фермы с учетом строительного подъема (рис. 1). Прогиб разыскивался по формуле Максвелла - Мора, усилия в стержнях вычислялись по программе [2], основанной на методе вырезания узлов. Известны работы по определению прогиба фермы или смещения ее опоры в аналитической форм для плоских ферм [3-8], пространственных [9-12], в вантовой системе [13]. Использованный метод индукции применим и для решения задачи о подвеске гироскопа [14] и для получения уравнений линий влияния плоских статически определимых ферм [15-17].

В обзорах [18-20] даны формулы для прогиба плоских ферм, полученные с использованием системы компьютерной математики Мaple. Аналитический подход применим и для задач с учетом реологии материала [21-23]. Обобщим решение [1] на случай произвольных сечений стержней. Выделим в ферме три группы стержней: стержни поясов длиной $f=\sqrt{a^{2}+c^{2}}$, раскосы длиной $g=\sqrt{(a+c)^{2}+b^{2}}$ и стойки высотой $c$. 


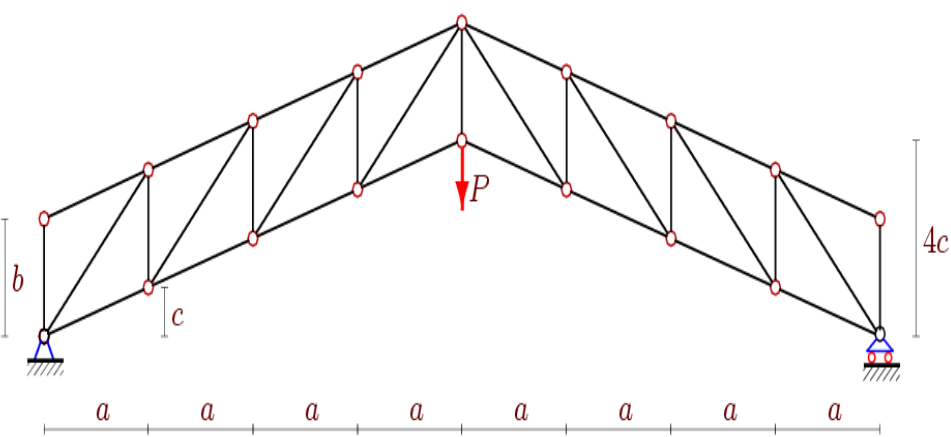

Рис. 1. Ферма с четырьмя панелями, $n=4$

Площади сечений групп стержней выразим через некоторую величину $F$ : $F_{i}=F / k_{i}$ с коэффициентами соответственно $k_{1}, k_{2}, k_{3}$. В [1] эти коэффициенты равны 1. Формула Максвелла - Мора приобретает вид

$$
\Delta=P\left(\sum_{i=1}^{m_{1}} \frac{S_{i}^{2} l_{i}}{E F_{1}}+\sum_{i=1}^{m_{2}} \frac{S_{i}^{2} l_{i}}{E F_{2}}+\sum_{i=1}^{m_{3}} \frac{S_{i}^{2} l_{i}}{E F_{3}}\right),
$$

где $S_{i}$ - усилия в стержнях от действия единичной силы, приложенной к середине пролета, $l_{i}$ - длины стержней. Результатом индукции явилась следующая формула: $E F \Delta=P\left\{F_{n} f^{3} k_{1}+n g^{3} k_{2}+b\left[(n+1) b^{2}+2 n^{2} c^{2}+4 b c n\right] k_{3}\right\} /\left(2 b^{2}\right) \quad$ ， где $F_{n}=n\left(2 n^{2}+1\right) / 3, c=H / n$. В процессе решения приходилось составлять и решать рекуррентные уравнения с использованием процедур Maple [2] rgf_findrecur и rsolve. Введем относительный прогиб $\Delta^{\prime}=E F \Delta / P$. В зависимости от числа панелей эта величина имеет явный минимум, приходящийся на 5-8 панелей (рис. 2) в зависимости от сечений стержней. Результаты получены при $L=2 a n=30 м, H=c n=2 м$.

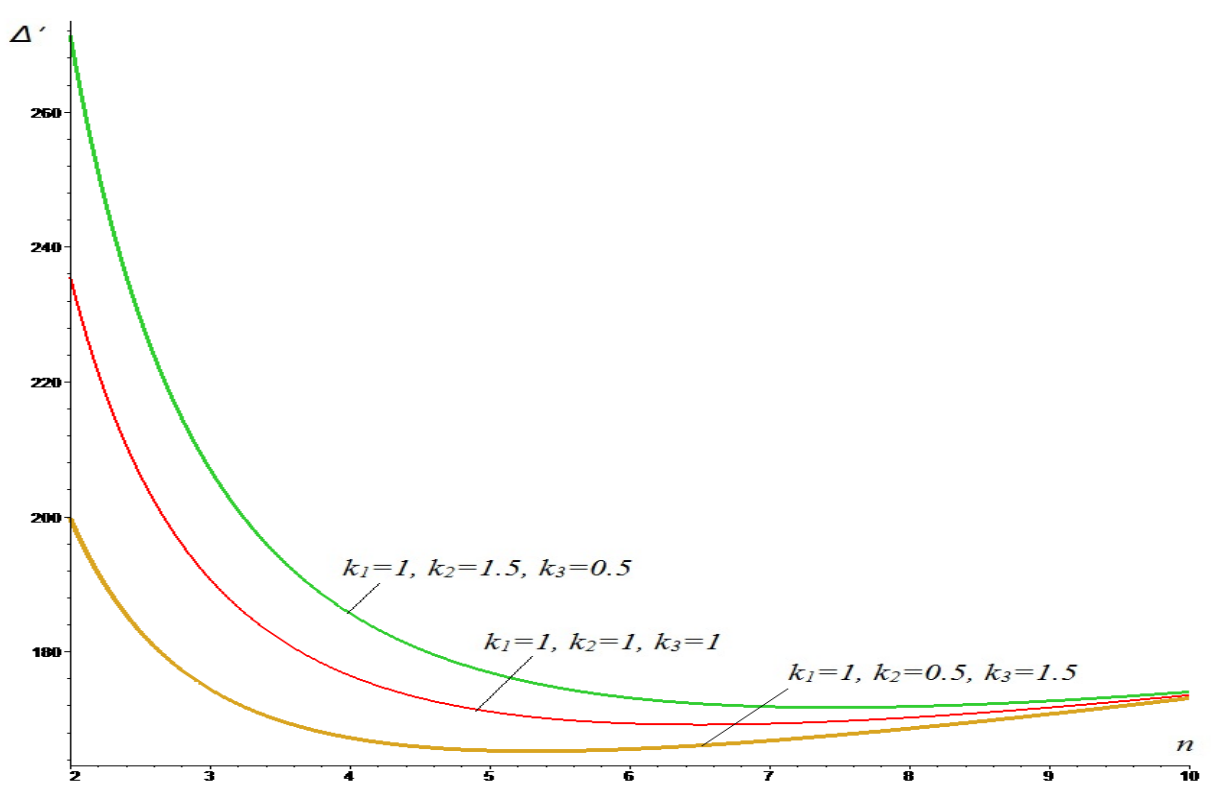

Рuс. 2. Прогиб фермы 


\section{Список используемых источников:}

1. Попов А.С. Прогиб балочной фермы с учетом строительного подъема в зависимости от числа панелей // Вестник научных конференций. 2015. №1-5(1). C.112-113.

2. Кирсанов M.H. Maple и Maplet. Решения задач механики. СПб.: Изд-во Лань, 2012. 512 c.

3. Кирсанов М.Н. Аналитическое исследование деформаций плоской фермы арочного типа // Вестник государственного университета морского и речного флота им. адмирала С.О. Макарова 2015.

№ 3 (31). C. 42-48.

4. Кирсанов М.Н. Математическая модель балочной фермы с элементами упрочнения // Инженерностроительный журнал. 2015. №4(56). С. 38-44.

5. Кирсанов М.Н. Точные формулы для расчета прогиба и усилий в стержнях ти5повой фермы «Молодечно» с произвольным числом панелей // Инженерно-строительный журнал. 2016. №1(61). C. 33-41.

6. Кирсанов М.Н. Расчет жесткости стержневой решетки // Вестник машиностроения. 2015. № 8.

C. 49-51.

7. Кирсанов М.Н. Формула для расчета прогиба балочной фермы с произвольным числом панелей // Научный журнал. 2016. № 6 (7). С. 6 - 8

8. Кирсанов М.Н. Аналитический расчет регулярной балочной фермы с произвольным числом панелей со сложной решеткой // Строительная механика и расчет сооружений. 2016. № 3. C. 16-19.

9. Кирсанов М.Н. Особенности аналитического расчета пространственных стержневых систем // Строительная механика и расчет сооружений. 2011. №5. С. 11-15.

10. Кирсанов М.Н. Аналитический расчет и оптимизация пространственной балочной фермы // Вестник МЭИ. 2012. № 5. С. 5-8.

11. Кирсанов М.Н., Андреевская Т.М. Анализ влияния упругих деформаций мачты на позиционирование антенного и радиолокационного оборудования // Инженерно-строительный журнал. 2013. №5(40). C. 52-58. 12. Леонов П.Г., Кирсанов М.Н. Аналитический расчет и анализ пространственной стержневой конструк-ции в системе Maple // Информатизация инженерного образования ИНФОРИНО-2014. 2014. C. 239-242.

13. Кирсанов М.Н. Статический расчет вантовой системы // Известия Московского государственного тех-нического университета МАМИ. 2013. Т. 1. № 3. С. 89-93.

14. Кирсанов М.Н. Жесткость торсионной подвески микромеханического волнового твердотельного ги-роскопа // Приборы и системы. Управление, контроль, диагностика. 2015. № 3. С. 18-22.

15. Al-Shahrabi A.M., Kirsanov M.N. Line of influence of the deflection for cantilever truss // Вестник научных конференций. 2016. № 2-1(6). С. 6-7.

16. Dong X., Kirsanov M.N. The dependence of the deflection of the truss from the position of the load for an arbitrary number of panels // Вестник научных конференций. 2016. № 1-4 (5). С. 6-7.

17. Jiang H., Kirsanov M. N. An analytical expression for the influence line of the truss // Вестник научных конференций. 2016. № 1-5(5). С.10-11.

18. Кийко Л.К. Аналитическая оценка прогиба арочной фермы под действием ветровой нагрузки // Науч-ный вестник. 2016. № 1 (7). С. 247-254.

19. Тиньков Д.В. Анализ точных решений прогиба регулярных шарнирно-стержневых конструкций //

Строительная механика инженерных конструкций и сооружений. 2015. №6. С. 21-28.

20. Тиньков Д.В. Сравнительный анализ аналитических решений задачи о прогибе ферменных конструк-ций // Инженерно-строительный журнал. 2015. №5(57). С. 66-73.

21. Тиньков Д.В. Оптимальная геометрия плоской балочной раскосной фермы с учетом линейной ползу-чести материала // Инженерно-строительный журнал. 2016. №1(61). C. 25-32.

22. Кирсанов М.Н. Оптимизация пространственной фермы с учетом ползучести материала // Известия высших учебных заведений. Строительство. 2001. № 10. С. 11.

23. Кирсанов М.Н. Оптимальная высота балочной фермы с учетом линейной ползучести материала // Известия высших учебных заведений. Строительство. 2000. № 5. С. 141.

(C) 2016, Попов A.C.

Прогиб балочной фермы с учетом строительного подъема в зависимости от числа панелей и распределения площадей стержней
(C) 2016, Popov A.S.

The deflection of the girder, including construction hoist, depending on number of panels and the distribution of areas rods 